\title{
PRINCIPLES ON THE BENEFITS OF MANUFACTURING PROCESS FLEXIBILITY*
}

\author{
By \\ William C. Jordan \\ Operating Sciences Department \\ General Motors Research Laboratories \\ Warren, Michigan 48090-9055 \\ Stephen C. Graves \\ Massachusetts Institute of Technology \\ WP \#3296-91-MSA \\ May 1991
}

*This paper has originally been published as a General Motors Research Publication, with the following reference:

Research Publication GMR-7310, General Motors Research Laboratories, 30500 Mound Road, Warren, MI 48090-9055 


\title{
PRINCIPLES OF THE BENEFITS OF MANUFACTURING PROCESS FLEXIBILITY
}

\author{
by \\ William C. Jordan \\ Operating Sciences Department \\ General Motors Research Laboratories \\ Warren, Michigan 48090-9055 \\ Stephen C. Graves \\ Sloan School of Management \\ Massachusetts Institute of Technology \\ Cambridge, Massachusetts, 02139
}

April 5, 1991

For presentation to the

MIT Leaders for Manufacturing Meeting April 25, 1991

Operations Research Society of America

May 12, 1991 


\title{
PRINCIPLES ON THE BENEFITS OF MANUFACTURING PROCESS FLEXIBIITY
}

\author{
William C. Jordan \\ Operating Sciences Department \\ General Motors Research Laboratories \\ Warren, Michigan 48090-8055 \\ Stephen C. Graves \\ Sloan School of Management \\ Massachusetts Institute of Technology \\ Cambridge, Massachusetts 02138
}

\begin{abstract}
Increasing manufacturing flexibility is a key strategy for efficiently improving market responsiveness in the face of uncertain future product demand. Process flexibility results from being able to build different types of products in the same plant or production facility at the same time. This allows changing the product mix during production as demand varies. This research has developed principles or guidelines about how process flexibility should be introduced into a netrork of plants (or other facilities) building many different products:

- Limited process flexibility (each plant building a fen products), configured in the right way, yields most of the sales and capacity utilization benefits of total flexibility (each plant building all products).

- Flexibility has the greatest benefits when it is configured to create few, long plant-product "chains" (groups of products and plants connected by product assignment decisions).

- There is not one optimal flexibility plan; there are numerous ways to assign products to plants that will achieve most of the benefits of total flexibility.
\end{abstract}




\section{INTRODUCTION}

Increasing manufacturing flexibility is a key strategy for efficiently improving market responsiveness in the face of uncertain future product demand. One type of flexibility results from being able to build different types of products in the same manufacturing plant or on the same production line at the same time. The literature on manufacturing flexibility of ten refers to this type of flexibility as "process flexibility" (see Browne, et al, 1984 and Sethi and Sethi, 1980). The purpose of this research is to help understand process flexibility, to show tow much of it is needed, and to show where it should be added to be most effective in responding to changes in product demand. While the focus of this research is the automotive industry, the conclusions are broadly applicable.

Process flexibility is determined by product assignment decisions, i.e., decisions on which products are built at which plants or on which lines. In the automotive industry, the products are vehicles defined at the nameplate level (e.g., Cherrolet Camaro, Pontiac Grand Prix, Buick Riviera). A vehicle assembly plant typically has a single assembly line, so we focus here on flexibility in the assignment of products to plants. These assignments are determined by tooling and capacity investment decisions that must be made between 1 and 3 years before production begins. Historically, the average difference between vehicle sales forecasts made in this period and actual annual vehicle sales is about $40 \%$ (both + and - ). Having process flexibility is one strategy for dealing with this uncertainty. The question is how much flexibility is needed?

Consider the assignments of products to assembly plants shown in Figure 1. These assignments are typical of flexibility levels that currently exist in the U.S. auto industry. Most plants build more than one product and a few products are built in more than one plant. Is the flexibility provided by these assignments enough to deal adequately with uncertain product demands? If not, how should they be changed to increase flexibility? The answers to these questions are not obvious. Other questions arise in determining which products to mix in a plant to achieve flexibility: To be truly responsive to uncertain customer demands is it necessary for every plant to be able to produce every product, or can equivalent benefits be achieved by having process flexibility only within groups of related products? Is the key to flexibility trying to identify products with negatively correlated demand and 


\section{PRODUCTS}

\section{PLANTS}
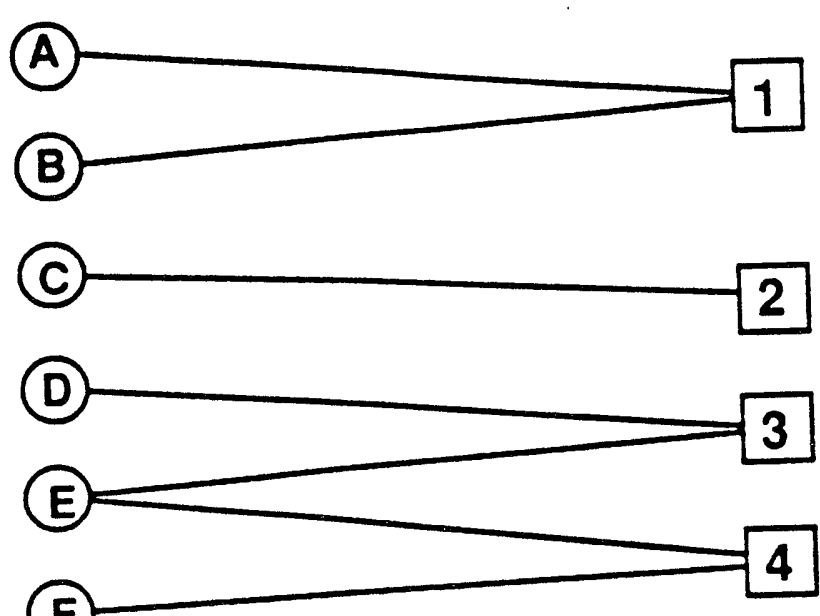

(F)

4
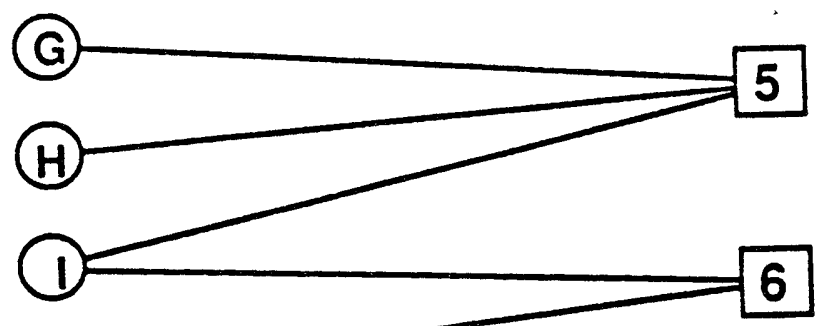

(1)

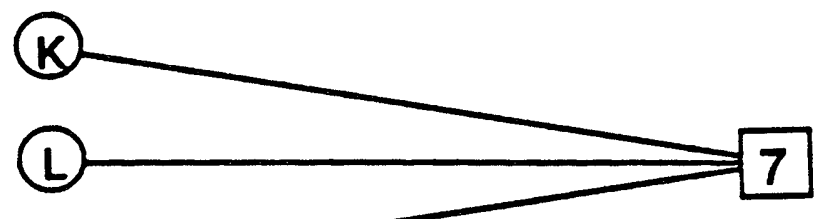

(iil)

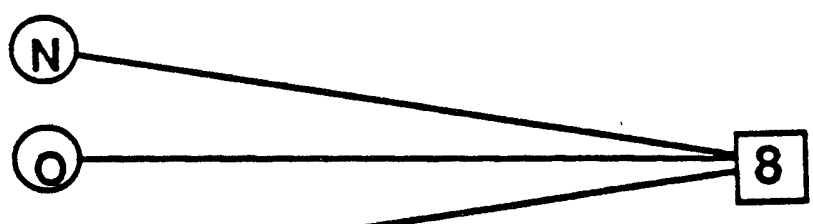

(P)

FIGURE 1. EXAMPLE PRODUCT ASSIGNMENTS. 
building them in the same plant? This paper will help answer these questions and provide guidelines for planning flexibility through product assignment and capacity decisions.

The literature on manufacturing flexibility has grown dramatically in the 1980's. Sethi and Sethi (1890) provide a very comprehensive survey of this literature. Much of this literature is directed at issues related to flexible manufacturing systems (FUS) which are "computer-controlled complexes of automated material handling devices and numerically controlled machine tools that can simultaneously process a variety of products" (Stecke, 1983). The focus on FUS means that deciding on how much flexibility to have is often modeled as whether to invest in 1) dedicated capacity with each module building a single product or 2) an FMS which can build all products (Fine and Freund, 1980). This approach may be appropriate in many cases, especially those involving machining operations; hovever, for assembly lines, the question is how much flexibility to invest in between the extremes of none and total. Andreou (1990) and Triantis and Bodder (1889) also present methods for computing the value of process flexibility. While providing insight on the factors that affect this value, the analytical approaches used are limited to considering only two products. Different methods are needed to show how much flexibility is needed for systems of many products and plants such as that in Figure 1 .

The next two sections describe the benefits of flexibility using a simple example. Following this, two sections describe principles related to:

- how much process flexibility is needed and

- how to add it to an existing set of plants to cope most effectively with uncertain demand.

Then we elaborate on these principles by applying them to the example in Figure 1. The final section discusses implications of these principles.

The focus of this paper is to develop the major issues related to flexibility in the context of capacity planning for automobile assembly. We describe a model that we have used to evaluate the benefits of process flexibility and then present the major findings from applying this model. In this first paper, we present and explain results rather than providing a rigorous derivation. A companion paper, Graves and Jordan (1991), provides the analytic demonstration supporting these findings. 
Because it provides the ability to change volumes of products produced in response to demand changes, the benefits of flexibility can be measured in increased expected sales and capacity utilization. We illustrate this here through a simple two-plant, tro-product example.

Before looking at how process flexibility provides benefits for coping with uncertain demand, it is important to note that it also has benefits even if demand is known with certainty. Consider two plants each with an annual capacity of 100 units. For tro products, $A$ and $B$, assume that demands are known with certainty as shown in Table 1a. While total demand matches total capacity, if each plant builds only a single product, as in Figure 2a, there are imbalances between each product's demand and the capacity available for building them. The result is that plant 1 has unused capacity and product $B$ has unfilled demand. Adding flexibility, as in Figure $2 b$ (in this deterministic case, flexibility rould actually only need to be added to plant 1), balances demand and capacity resulting in greater sales and capacity utilization.

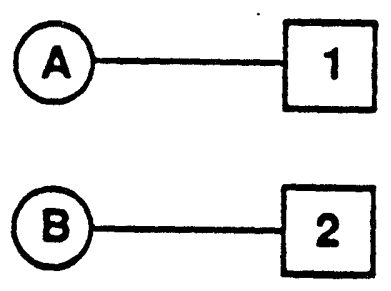

a) Dedicated Plants

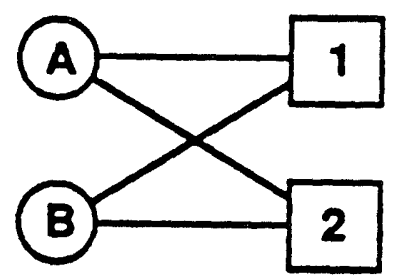

b) Flexible Plants

\section{O. PRODUCTS $\square$. PLANTS}

FIGURE 2. PRODUCT ASSIGNMENTS FOA 2-PRODUCT, 2-PLANT EXAMPLE. 
Table 1. Annual Product Demands for 2-Product, 2-Plant Example.
a) Deterministic Case

$\begin{array}{cc}\text { Product } & \frac{\text { Demand }}{80} \\ \mathrm{~B} & 110\end{array}$

b) Stochastic Case - Demand Distributions for each of Products $A$ and $B$

\begin{tabular}{cc} 
Demand & Probability \\
\hline 50 & $1 / 3$ \\
100 & $1 / 3$ \\
150 & $1 / 3$
\end{tabular}

To understand the benefits of flexibility for dealing with uncertain demand, reconsider this example with probabilistic demand as shown in Table 1b. We assume that products $A$ and $B$ have the same demand distribution, but that the product demands are independent. Demand uncertainty creates uncertainty in sales, capacity utilization, and lost sales in the following way. We assume that the production levels can be set after observing the demand levels. When demand exceeds plant capacity, we assume that the excess demand is lost and that sales just equal the plant capacity.

With each plant dedicated to a single product, as in Figure 2a, we can compute expected sales, lost sales, and capacity utilization. For instance, actual demands will be 50 units for $A$ and 150 units for $B$ with a $1 / 9$ chance. In this case, sales will be 50 units for product $A$ and 100 units for $B$, lost sales are 0 units for $A$ and 50 units for $B$, and overall capacity utilization is 75\% (150 units/200 units). Considering similarly all possible combinations of demand, overall expected sales is 167 units, expected lost sales is 33 units, and expected capacity utilization is $83 \%$.

With this example we can show how adding flexibility, as in Figure $2 b$, effects sales and capacity utilization. Let each plant now build both products in any proportion within its capacity. All other data are the same. Now when actual demands are 50 units for $A$ and 150 units for $B$, production in the plants can be shifted so that all demands are filled and capacity is fully utilized. With flexible plants, overall expected sales is 178 units, expected lost sales is 22 units, and expected capacity utilization is $89 \%$.

This example illustrates that increasing process flexibility increases 
both expected sales and capacity utilization by providing the ability to change product mix in response to unforeseen demand changes. In this example, total annual expected demand equals total annual capacity at 200 units. Next, we examine how the benefits from flexibility depend on capacity decisions. Further, we show how adding flexibility is equivalent to changing capacity to achieve sales and capacity utilization objectives.

\section{RELATIONSHIP BETWEEN FLEXIBILITY AND CAPACITY DECISIONS}

To see the basic relationship between flexibility and capacity consider some extreme cases. If for the stochastic demand case, plant capacities are set at the minimum possible demand (50 units), each plant is fully utilized under any possible demand. Adding flexibility has no value. At the other extreme, if capacities are set at the maximum possible demand (150 units), all demand would always be filled and again flexibility rould have no value.

To see how the value of flexibility changes when plant capacities are varied, we set the total annual capacity for the two-plants at the following levels: $100,130,150,170,200,230,250,270$, and 300 units (capacity is always split equally between the plants). Expected sales and capacity utilization are calculated for each capacity level both without and with flexibility (i.e., the product assignments in Figures $2 a$ and $2 b$, respectively). Results are plotted on the graph in Figure 3 . The solid line FDAHG shows, when there is no flexibility, how expected sales and utilization change with changes in capacity. The solid line FEBG shows, when there is total flexibility, how these quantities change. The dashed lines show the impact of adding flexibility at a given capacity level. For example, point D plots expected sales and utilization when total capacity equals 230 units and there is no flexibility. Point $E$ shows the impact of adding total flexibility at the same capacity.

This graph shows that the benefits of adding flexibility are relatively independent of the aggregate levels of capacity and expected demand. Certainly, if total capacity deviates far enough from expected demand, then flexibility has little or no value. However, in this example, the benefits of flexibility are relatively constant even when capacity is $25 \%$ above or below expected demand. While these numbers are specific to this example, the general result applies to more realistic situations generally. This is a very 


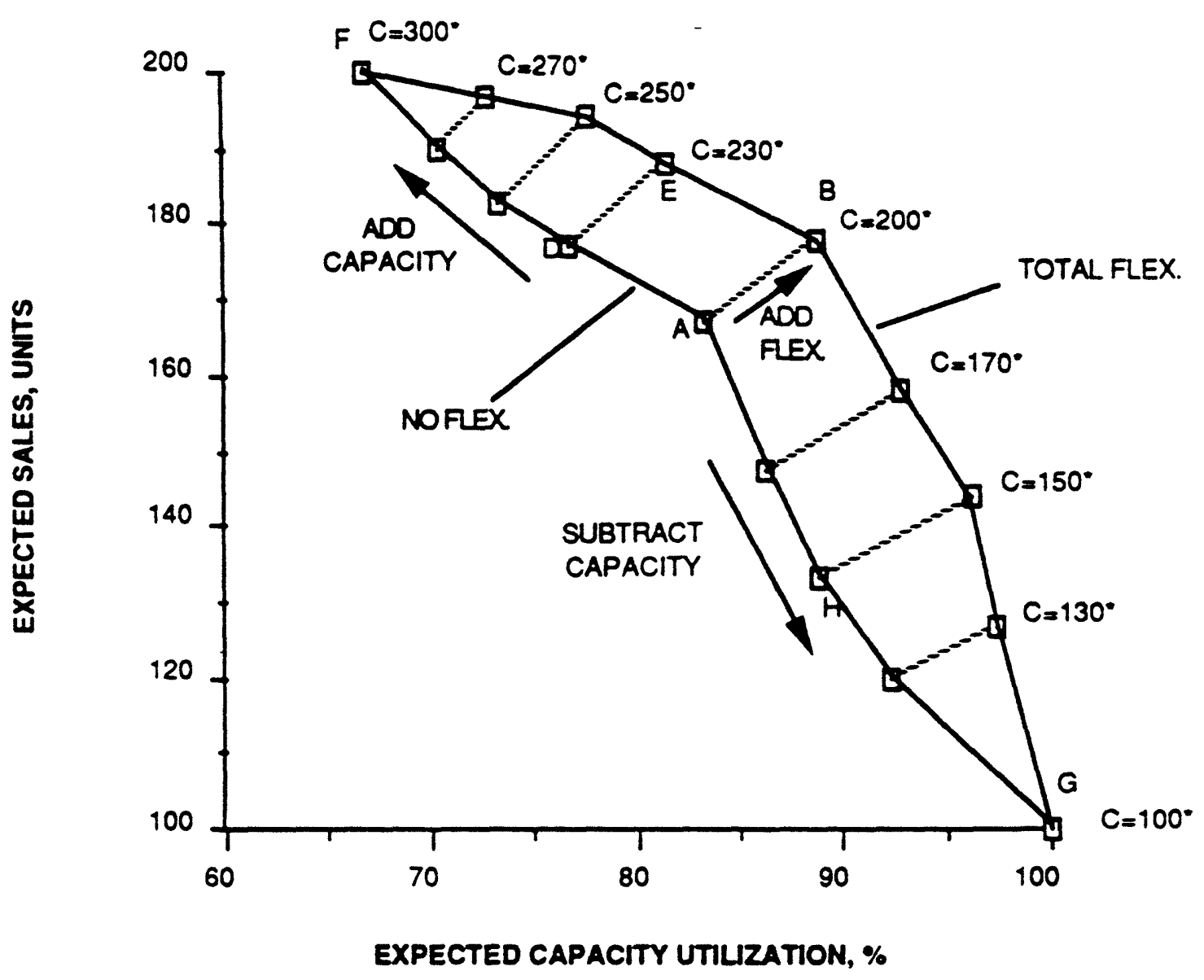

- C=TOTAL UNITS OF CAPACITY; ASSUMED EQUALLY SPLIT BETWEEN PLANTS

FIGURE 3. IMPACT OF CAPACITY CHANGES ON BENEFITS OF FLEXIBILITY. 
important result because expected product demand is quite dynamic. This result says that we only need capacity roughly in balance with expected demand to get sales and utilization benefits from adding flexibility.

Figure 3 also shows that adding flexibility can be substituted for changing capacity to reach sales and capacity utilization goals. For example, with no flexibility and a total capacity of 200 units (point A), expected sales are 167 units. Expected sales could be increased to about 178 units either by adding total flexibility (point B) or by adding 15 units of capacity to each plant (point D). The graph also shows that adding flexibility increases capacity utilization, while adding capacity sacrifices capacity utilization.

Likewise, capacity utilization goals could either be reached by changing flexibility or changing capacity. That is, with no flexibility and a total capacity of 200 units (point A) expected capacity utilization is $83 \%$. If the goal is to attain $80 \%$ expected capacity utilization, either total flexibility could be added (point B) or 25 units of capacity could be subtracted from each plant (point B).

The purpose of these examples has been to demonstrate the benefits of process flexibility and how flexibility decisions relate to capacity decisions. The key observations we have made about process flexibility to this point are:

1. Adding it increases both expected sales and capacity utilization.

2. Flexibility achieves these benefits by i) allowing the product mix in plants to be changed during production in response to unforeseen demand variations and by $i i)$ better balancing expected demand with capacity.

3. In contrast to flexibility, adding capacity increases expected sales but decreases expected capacity utilization. Subtracting capacity has the opposite effect.

4. Adding flexibility can, to some extent, be substituted for changing capacity to reach sales or capacity utilization goals.

5. The benefits of flexibility remain significant as long as total 
capacity is roughly balanced with expected demand.

With this background, we will now develop principles that provide guidelines for investing in process flexibility.

\section{BOW WUCH FLEXIBILITY IS ENOUGH?}

If a manufacturing firm only has two products and two plants, making decisions about flexibility is easy. However, with many products and many plants, these decisions become very complex for several reasons. First, the sales and utilization benefits of flexibility are very difficult to calculate when there are multiple products and plants. Second, the number of possible product assignment configurations grows exponentially with the number of products and plants. With $M$ products and $N$ plants, there are on the order of $2^{\mathrm{WN}}$ possible configurations. So, with 2 products and 2 plants there are 7 possible configurations: $(1-A, 2-B),(1-B, 2-A),(1-A B, 2-A),(1-A, 2-A B)$, $(1-A B, 2-B),(1-B, 2-A B)$, and $(1-A B, 2-A B)$, where $1-A$ denotes that plant 1 builds product $A$, etc.. $A$ more realistic case with 15 products and 15 plants has about $5 \times 10^{67}$ configurations. To help sort through these, this section and the one that follows develop principles that can be used as guidelines for identifying reasonable product assignment configurations and for thus limiting the search.

To understand how to create good scenarios, we will develop our intuition for how benefits accrue as we add more and more flexibility. To do this, we consider a 10-product, 10-plant example. To keep the example simple, assume that each plant has a capacity of 100 units and that the expected demand for each product is also 100 units. The demand for each product is from a truncated Normal Distribution with a standard deviation of 40 units, and the minimum and maximum possible demands for each product are 20 and 180 units, respectively. This level of uncertainty is comparable to uncertainty historically seen in demand forecasts used for planning purposes in the auto industry. Again, we assume that product demands are independent.

For this example, we wish to compute the expected sales and capacity utilization for different product assignment configurations. For more than two products and plants doing this using analytical methods is extremely difficult. Therefore, we use a simulation model to compute this information 
for any set of product assignment decisions. That is, we 1) randomly sample the demand for each product, 2) allocate this demand to plants to maximize the demand filled (i.e., sales) subject to product assignment decisions and capacity constraints, and 3) collect statistics on sales, lost sales, and capacity utilization for this realization of demand. This procedure is repeated iteratively a sufficient number of times to produce reliable estimates of expected sales and capacity utilization.

The product assignments shown in Figure 4 allon for no flexibility. For this configuration, expected sales are 853 units and expected capacity utilization is $85 \%$. Having total flexibility (each plant builds all products) increases both expected sales and expected capacity utilization to 954 units and $95 \%$, respectively. Although total flexibility may be unrealistic from an investment and manufacturing cost viewpoint, it provides a good benchmark to measure the effectiveness of other, more reasonable configurations.

An important question is how much flexibility is needed to have significant sales and utilization benefits? Put another way, can the benefits of total flexibility be achieved with something less than total flexibility? To answer this, consider adding flexibility incrementally to the no flexibility configuration in Figure 4. That is, we add one "link" (i.e., assign one new product to one plant) at a time to the configuration and measure the impact on sales and utilization using the simulation model. We first add product $A$ to plant 2 , then product $B$ to plant 3 , then product $C$ to plant 4, and so on. The tenth link added assigns product $J$ to plant 1 . This pattern for adding flexibility is not chosen arbitrarily; it is one that yields the greatest benefits and is chosen based on some generic principles that will be discussed below.

Figure 5 shows the expected sales and utilization impacts of adding these links. Adding each increment of flexibility yields increasingly greater sales and utilization benefit until, after adding the tenth link, over $95 \%$ of the sales and utilization benefits of total flexibility have been achieved. Figure 6 summarizes this result: adding 10 links to achieve the configuration in Figure $6 a$ has about the same benefits as adding 90 links to achieve total flexibility as in Figure $6 b$.

Keep in mind that Figures 5 and 6 do not show that building two products in every plant and having each product built in tro plants is always the right level of flexibility to have. The number of products per plant, plants per product, and the product assignments required to achieve the sales and 
PRODUCTS

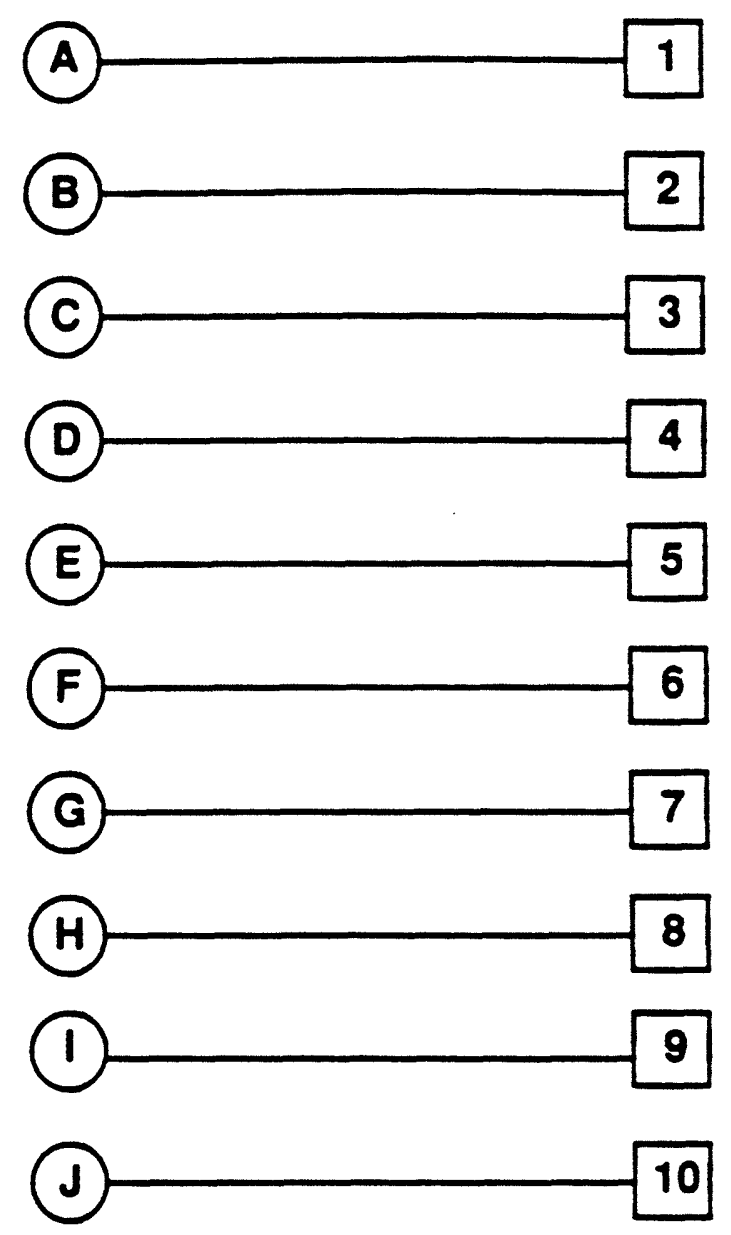

FIGURE 4. 10-PRODUCT, 10-PLANT EXAMPLE - WITHOUT FLEXIBILITY. 


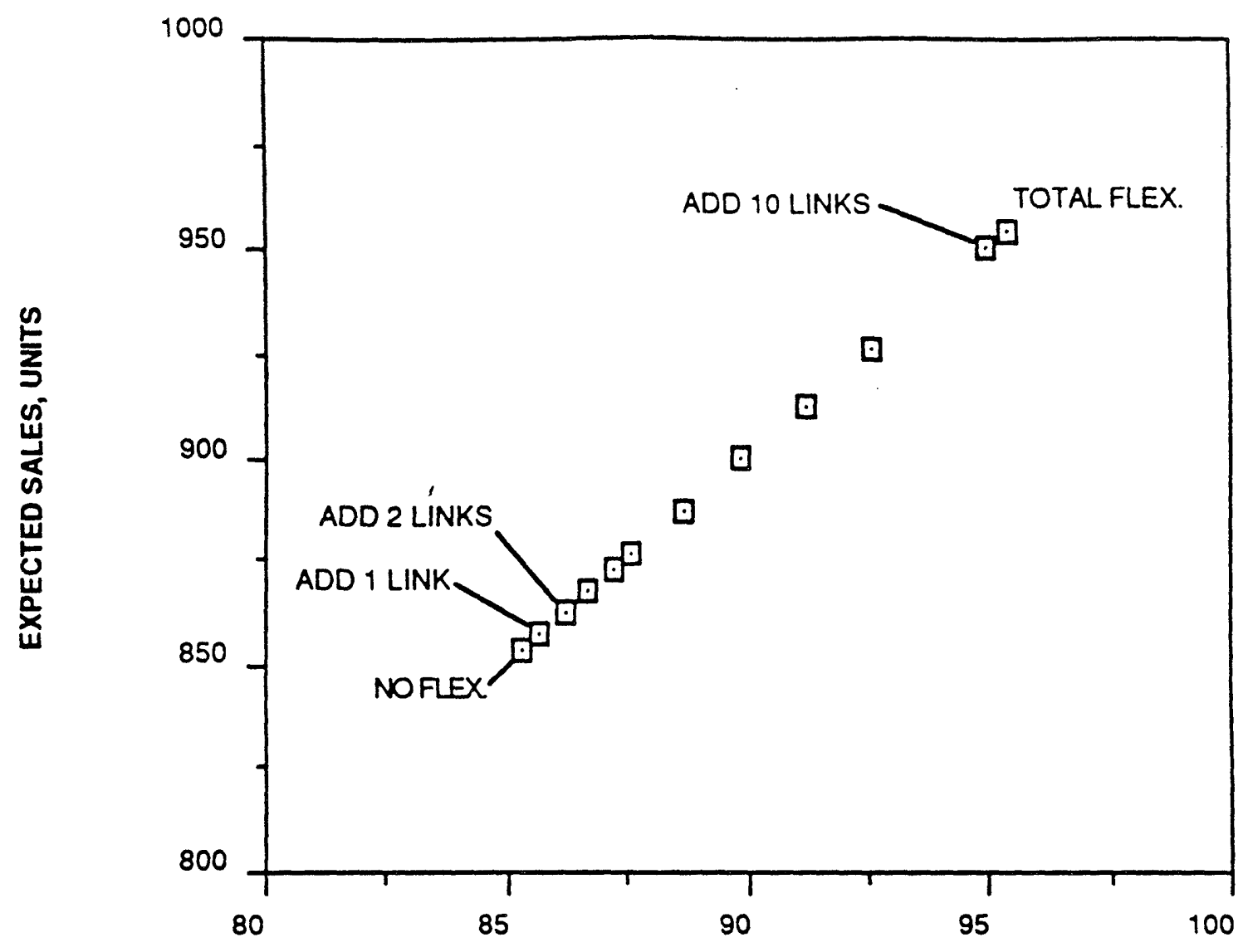

EXPECTED CAPACITY UTILIZATION, \%

FIGURE 5. IMPACT OF INCREMENTALLY ADDING FLEXIBILITY ON EXPECTED SALES AND CAPACITY UTILIZATION. 


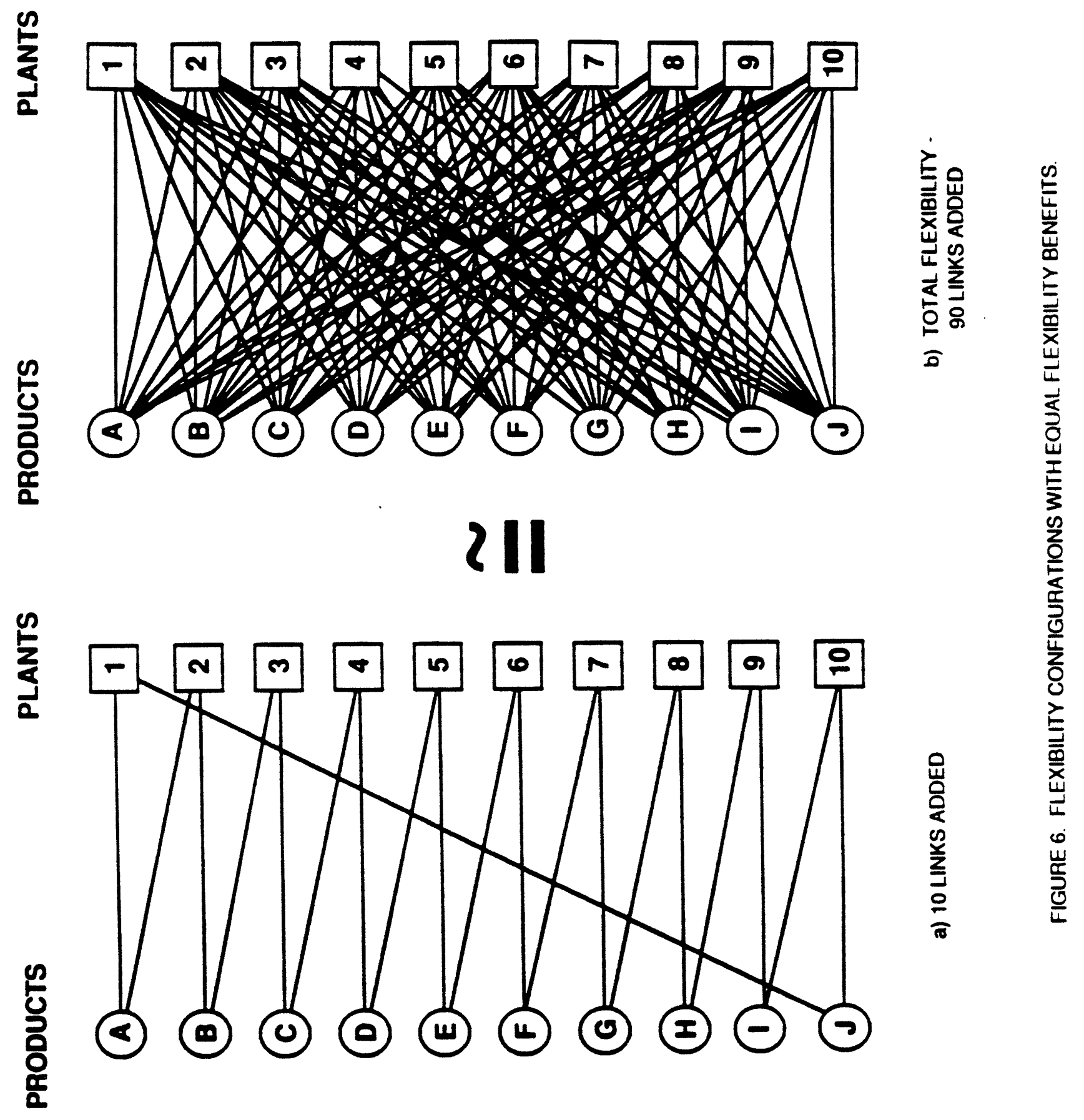


utilization benefits of total flexibility depend on the specific number of products and plants, plant capacities, product expected demands, and demand uncertainty levels. The point here is that to obtain the benefits of total flexibility for the system does not require that each plant be totally flexible; rather, a little flexibility can achieve almost all the benefits of total flexibility.

We have said nothing to this point about the costs of achieving flexibility. Figure 5 does not identify hor much flexibility to invest in for this specific example, but does show that investing in 10 new "links" to yield the configuration in Figure $6 a$ would yield the benefits of total flexibility and that adding flexibility beyond this point is probably not worthwile. To determine the best configuration requires that sales and utilization benefits, as shown in Figure $6 b$, be traded of $f$ against the investment and manufacturing costs associated with each level of flexibility. We will talk more about manufacturing costs in the Discussion section of this paper.

This section has shown that a little flexibility can achieve nearly all the benefits of total flexibility. However, flexibility must be added carefully if it is to be effective. Earlier, we referred to generic principles that were used to add the flexibility that resulted in the configuration in Figure 6a. The next section develops these principles.

\section{WHERE SHOULD FLEXIBILITY BE ADDED?}

To decide where to add flexibility, we have discovered that the concept of "chaining" is important. A "chain" is a group of products and plants which are all connected, directly or indirectly, by product assignment decisions. Figure 7 shows an example of 2 chains. Within a chain, a path can be traced from any product or plant to any other product or plant via product allocation links. No product in a chain is built by a plant from outside that chain; no plant in a chain builds a product from outside that chain. In terms of graph theory, a chain is a connected graph.

Chaining is important for achieving the benefits of flexibility because all products within a chain essentially share that chain's capacity, even without each plant building all products. To see this, consider chain 2 in Figure 7. Products $C$ and $D$ share the capacities of plants 2 and 3 even though each is built in only one of the plants. For example, if demand for product $C$ 


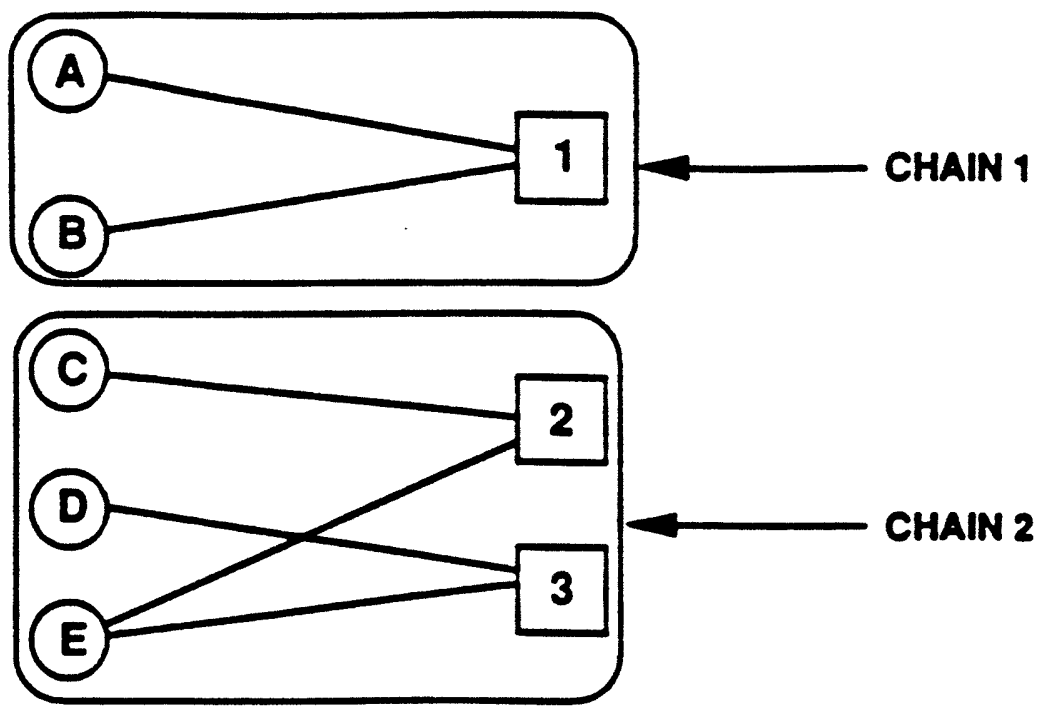

FIGURE 7. EXAMPLES OF "CHAINS".

is belon expected levels, it can give up capacity in plant 2 that can then be used by product $E$. This frees up capacity in plant 3 that can be used by product $D$ if its demand should happen to be higher than expected.

The impact that chaining has on expected sales is demonstrated by comparing the two configurations in Figure 8 for the example discussed in the previous section (Figure $8 \mathrm{a}$ is the same as Figure $6 \mathrm{a}$ ). By some measures, both configurations have the same level of flexibility: both have 20 product-plant "links" with two products built in each plant and each product built in two plants. Howerer, the configuration in Figure 82 has one chain, while that in Figure $8 b$ has fire. As a consequence, these tro configurations are far from equal in their sales and capacity utilization performance, as Table 2 shows. The one chain configuration yields orer $95 \%$ of the increase in expected sales from total flexibility. Bowerer, haring the same number of products per plant configured in fire chains rields less than half of these benefits. The benefits of flexibility for responding to unforeseen changes in demand does not come only from having more products assigned per plant, but also from creating longer chains. 


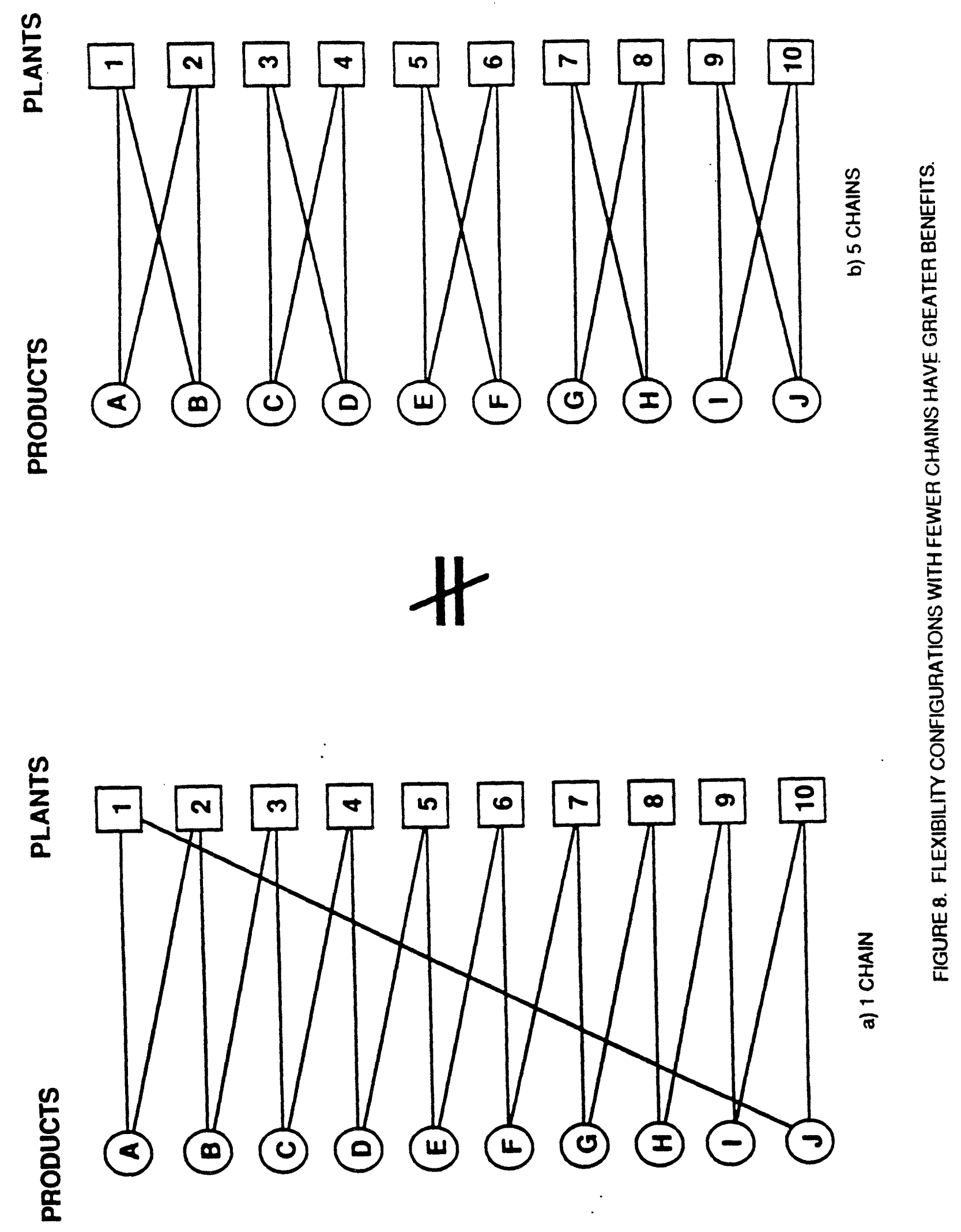


Table 2. Expected Sales for Different Flexibility Configurations.

$\begin{array}{cc}\text { Configuration } & \frac{\text { E[Sales] }}{853 \text { units }} \\ \text { no flexibility (Figure 4) } & 896 \\ 20 \text { links in 5 chains (Fig. 8b) } & 850 \\ 20 \text { links in 1 chain (Fig. 8a) } & 954 \\ \text { total flexibility (Fig. 6b) } & \end{array}$

The intuition behind this concept is easy to grasp. The longer the chain of products and plants, the greater the opportunities are for shifting capacity from building products with lower than expected demand to those with higher than expected demand. In Figure 8 , if product $A$ 's demand is greater than expected and product G's is less than expected, with one long chain the volume of products built in each plant can be shifted to accommodate increased production of $A$ and decreased production of $G$. With 5 chains, as in Figure $8 b$, such a production shift could not be accomplished. The appendix develops an analytical model which demonstrates generally the benefits of chaining.

To this point, we have developed one clear guideline for adding flexibility: to be most effective for increasing sales, flexibility should be added to create fewer and longer chains for products and plants. This does not imply, however, that only enough flexibility should be added to create one chain. In our example, removing product $J$ from plant 1 in Figure $8 a$, still results in a single chain. Expected sales and utilization for this chain (without the product J-plant 1 link) are 929 units and $92.9 \%$, respectively. Adding in the link between product $J$ and plant 1 , however, significantly increases expected sales to 950 units and capacity utilization to $95.0 \%$. The reasons for this are clear: without the $\mathrm{J}-1$ link, there are no options for accommodating higher than expected demand for product $J$ or for using the capacity of plant 1 if product $A$ 's demand is lower than expected.

The implication of this is that once enough flexibility has been added to create a chain, a little more flexibility may be needed to reach the benefits of total flexibility. However, it is difficult to prescribe general guidelines for how flexibility should be added within a chain. For the idealized example in Figures 4-6 where the number of plants and products are equal and expected demands and capacities are identical, there is a specific way in which this flexibility must be added: to be most effective it must "close the chain" (in terms of graph theory, we want to create a cycle). That 
is, adding the link between product $J$ and plant 1 creates a complete circuit around which production can be varied in response to demand changes. Further, it balances the number of products/plant and plants/product throughout the chain.

For more realistic cases, the idea of adding flexibility to create a complete circuit does not necessarily apply and we have no firm guidelines for adding flexibility within a chain. However, based on this example and on tests with real products and plants, the following guidelines are helpful for identifying the best way to add flexibility once a single chain has been formed:

- try to equalize the number of plants (measured in total units of capacity) that each product in the chain is directly connected to,

- try to equalize the number of products (measured in total units of expected demand) that each plant in the chain is directly connected to, and

- try to create a circuit(s) that encompasses as many plants and products as possible.

We will illustrate these guidelines in a more realistic example below.

The last two sections have developed the following flexibility principles:

1. A little flexibility can yield most of the benefits of total flexibility.

2. Flexibility is most effective at increasing expected sales and capacity utilization when it is added to create longer chains of plants and products.

3. Once a plant-product chain has been created, a little more flexibility may have some benefit. This flexibility should be added in a way that better balances the assignment of products to plants, and/or that creates circuits. However, there are rapidly diminishing benefits to adding more flexibility within the chain. 


\section{CASE STUDY}

To show how these principles can be applied to help make decisions on flexibility for real situations, this section presents a case study based on a real set of vehicles and assembly plants. The specific numbers used in this study have been adjusted to protect proprietary data, but the magnitudes of product demands and uncertainty levels are typical of those for automobiles at the nameplate level (e.g., Chevrolet Camaro). Also, the plant capacities used are representative of automobile assembly plants.

Figure 8 shows the plants and products used in this example. It also shows expected demand for each product, plant capacities, planned product assignments, and the resulting product-plant chains. The product assignments are those shown in Figure 1. Table 3 provides the additional data used in this case study. In earlier examples we have assumed uncorrelated product demand. In this case study, the sixteen vehicles considered fall into three groups: products 1 to 6 (compact cars), products 7 to 13 (full-sized cars), and products 14 to 16 (luxury cars). We assume that product demands for pairs of vehicles within the same group are positively correlated as shown in Table

3. We assume for pairs of products across groups that demands are independent. Table 3 also shows tooling capacities, i.e., limits on the production of specific products at each plant.

With this data, the simulation model was used to calculate how these product assignments and changes to them impact expected sales and capacity utilization. For the base assignments, expected sales and capacity utilization are 1.76 million and $86.6 \%$. Having total flexibility at each plant would increase expected sales by $9.1 \%$ to 1.92 million units capacity utilization to $94.7 \%$. To find out how much flexibility would have to be added to achieve the benefits of total flexibility, nen product assignment links were added one-by-one to those in Figure 9 . These added links chain the products and plants together, as shown in Figure 10 . They were added based on the priniciples from the preceding sections, and because, based on output from the simulation model, they connected products with high expected lost sales with poorly utilized plants. The number by each new link shows the order in which they were added.

Figure 11 shows how adding each new link affects expected sales and capacity utilization. After adding six links, $84 \%$ of the sales and utilization benefits of total flexibility (i.e., $94 \%$ of the difference between 


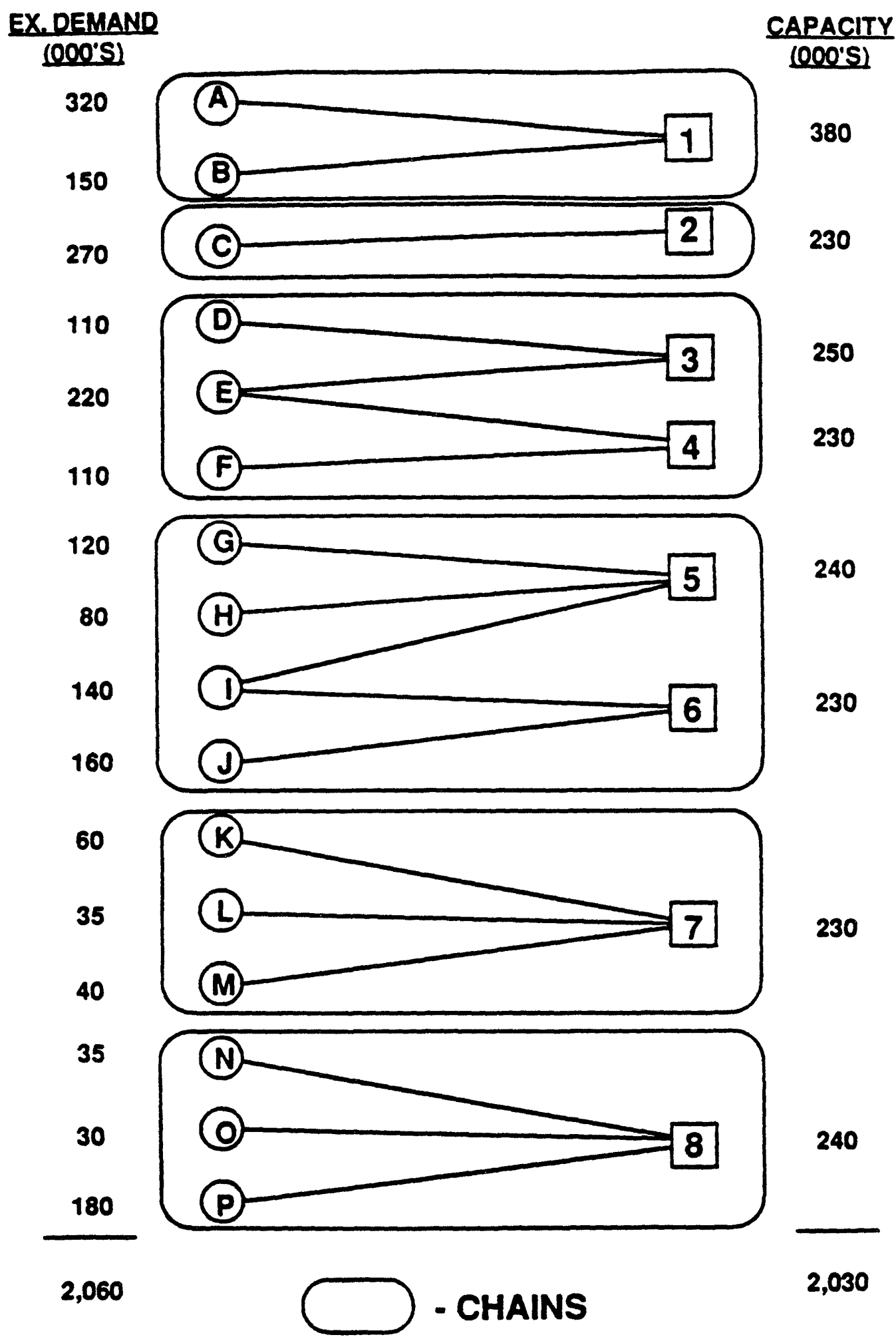

FIGURE 9. CASE STUDY PRODUCTS, PLANTS, CHAINS, BASE ASSIGNMENTS, EXPECTED DEMANDS, AND CAPACITIES. 
Table 3. Demand Uncertainty and Capacity Data for Case Study.

\section{Demand Data}

Product demands assumed normally distributed truncated at a minimum and maximum demand:

- expected demand per year - see Figure $\theta$.

- standard deviation in demand - $40 \%$ of the expected demand.

- minimum demand - two standard deviations below the expected demand.

- maximum demand - tro standard deviations above the expected demand.

- demand correlation coefficients

- 0.3 for pairs of products within the same group. The three product groups in this example are products $\Lambda-F, G-4$, and $N-P$.

- 0.0 otherwise.

\section{Capacity Data}

- Plant capacities - see Figure 9.

- Tooling capacities - for plants building multiple products, the tooling capacity for each product is assumed to be $80 \%$ of the plant capacity.

total flexibility and the base assignments) have been achieved. That is, adding six links to create one product-plant chain has the same benefits as adding 110 links (building every product in every plant). While adding more flexibility could marginally improve expected sales and utilization, there would be little point to investing in flexibility beyond this point.

There are many ways to add six links to the initial assignments in Figure 9 to create one chain. Not all have equal benefits, however, there are many different plans that do have nearly all the benefits of total flexibility. Figure 10 shows one plan; Figure 12 shows another that yields virtually identical sales and utilization benefits. The key point is that there is not one "optimal" flex plan. Rather there are many that are near-optimal. 


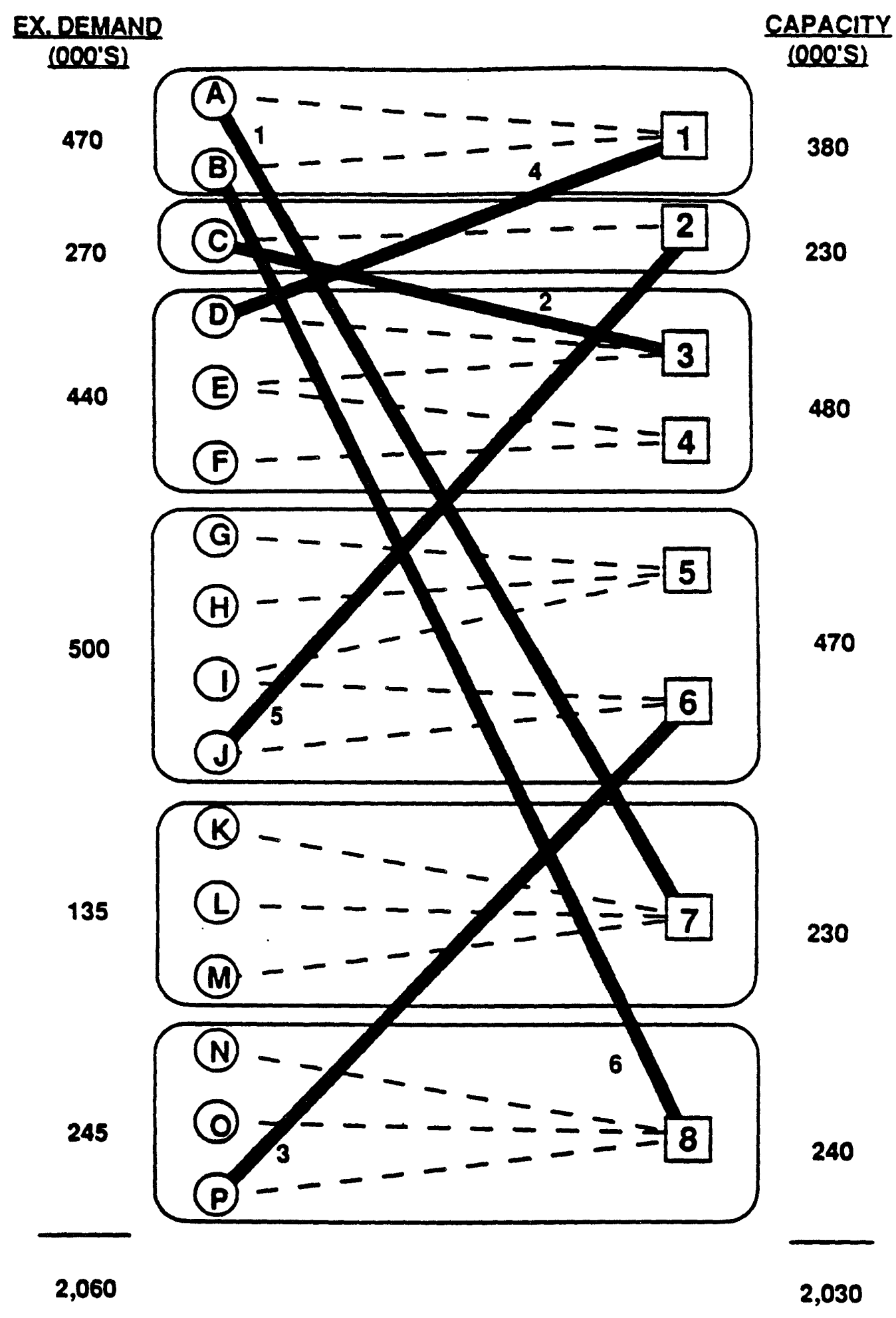

FIGURE 10. PRODUCT ASSIGNMENT LINKS ADDED TO CREATE ONE CHAIN. 


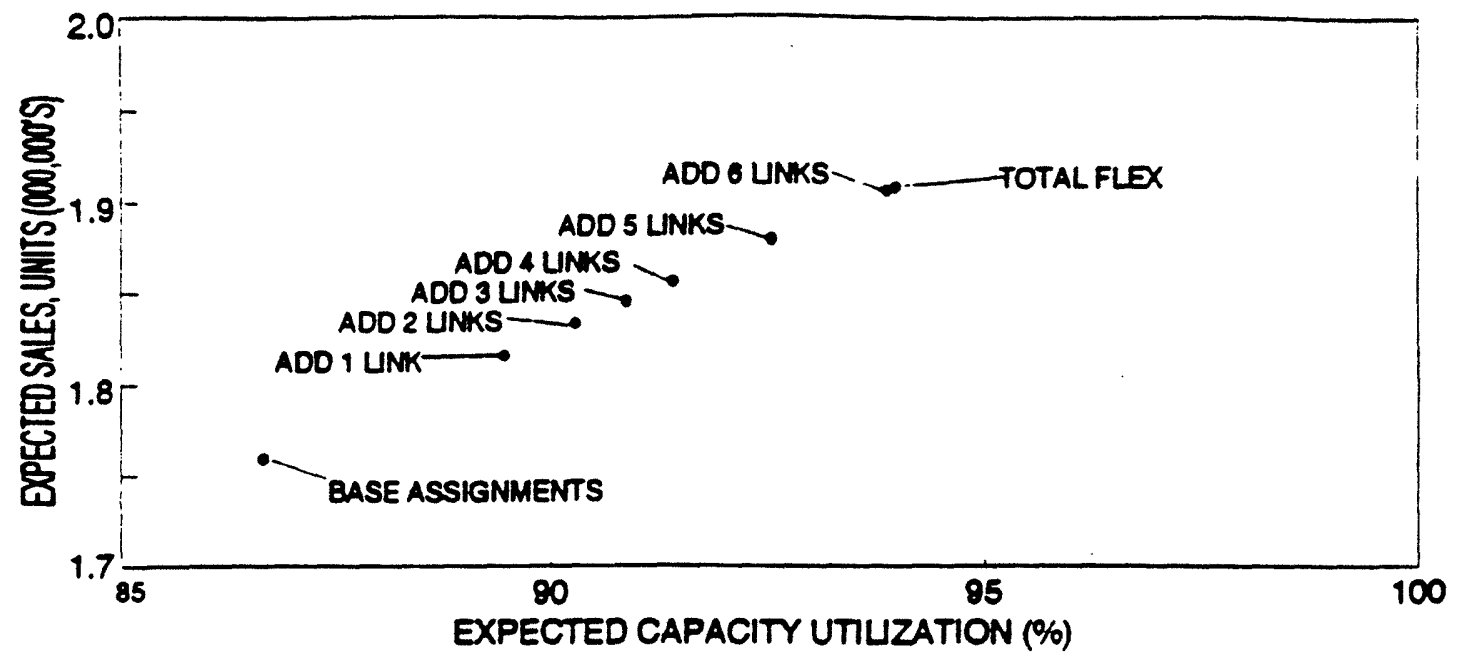

FIGURE 11. EXPECTED SALES AND CAPACITY UTIUZATION AS FLEXIBILITY IS ADDED TO CASE STUDY PRODUCT ASSIGNMENTS.

\section{DISCUSSION}

This paper has developed principles for hor much flexibility is needed and where it should be added to respond most effectively to uncertain demand. The key ideas are that

1. a small amount of flexibility added in the right way can have all the benefits of total flexibility and

2. the right way to add this flexibility is to create ferer, longer plant-product chains.

Although developed and presented in terms of automobile assembly plants, these principles are quite general and apply to all types of products and manufacturing operations, in which there are parallel facilities producing multiple products.

These principles focus on hor to achieve and quantify the benefits of flexibility. However, they also imply something about the costs of adding flexibility. First, many people faced with inresting in flexibility fear excessive costs because they assume that to be beneficial flexibility must mean that each plant will have to build asay or all products. We have demonstrated here that this is not the case. Automotive manufacturers can get the benefits of total flexibility in rehicle assembly without increasing 


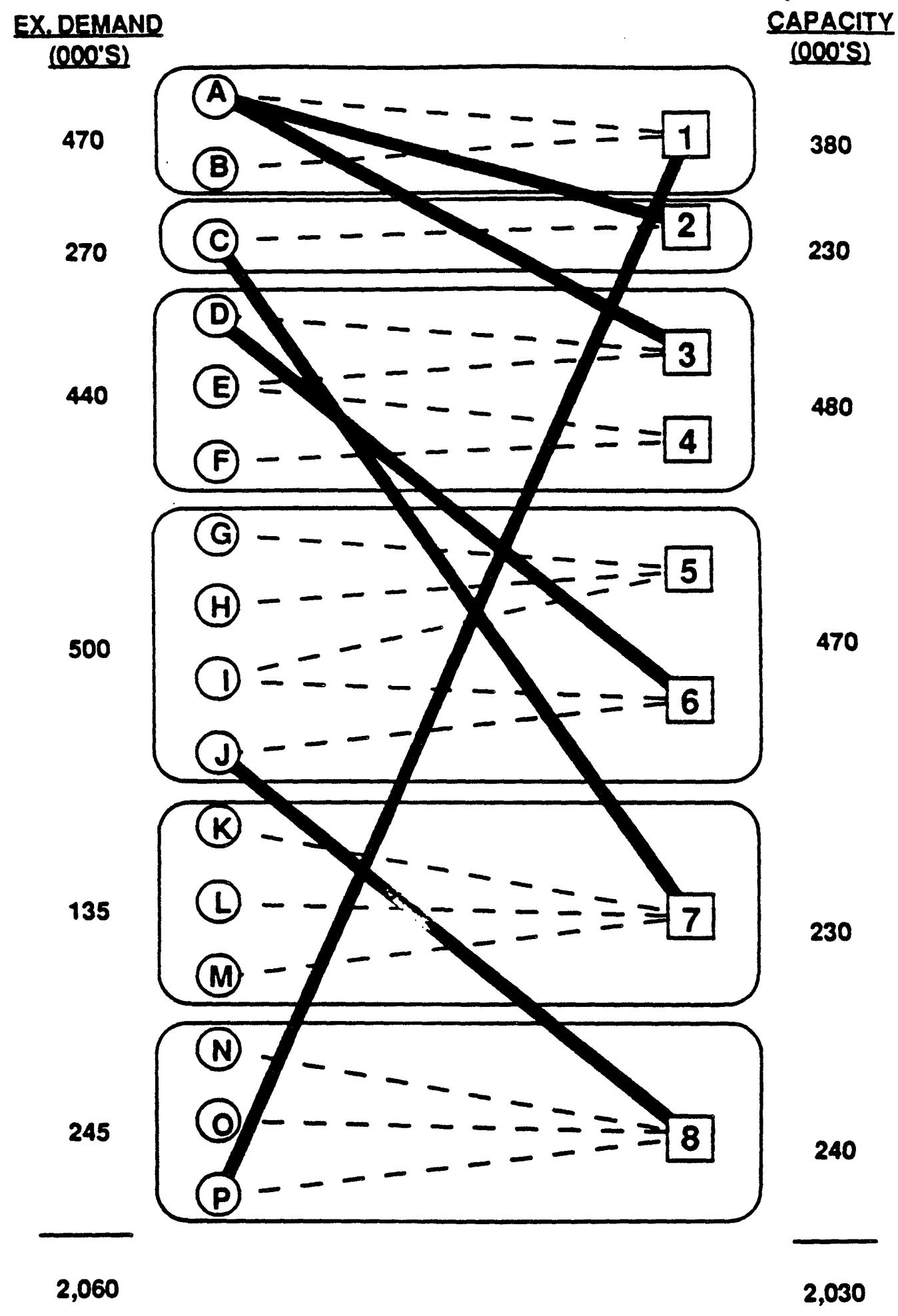

FIGURE 12. ALTERNATIVE ADDED LINKS THAT YIELD

VIRTUALLY IDENTICAL BE: :-TITS TO FIGURE 10 ASSIGNMENTS. 
significantly the number of products each plant builds. For the case study example, building only tro to four products in each plant (see Figures 10 and 12) provides almost all the benefits of total flexibility at a fraction of the cost.

Second, people may fear that adding flexibility will be expensive because it means that each plant will have to build extremely diverse products. Again, the results demonstrated here show that this is not necessary. The principle of chaining implies that the benefits of total flexibility can be realized by building fairly similar products in the same plant. That is, becoming flexible does not require that all plants build, for example, cars and trucks. Rather, flexibility can be achieved by chaining if one plant builds a truck and $a$ van and another builds the van and a car together. It is creating longer product-plant chains that results in flexibility benefits, not building diverse products in a single plant. This certainly suggests strategies for lowering the cost of achieving flexibility.

Third, costs may be lower than anticipated because, as the case study illustrated, there is not one optimal product assignment plan for achieving the benefits of flexibility. This means that there are opportunities for choosing an effective flexibility plan that also minimizes inrestment and manufacturing costs.

These flexibility principles also imply hor flexibility and capacity planning should be performed. Often flexibility is planned by just focusing on only a few products with negatively correlated demand (i.e., products such that if the demand for one is higher than expected, the demand for the other is probably below what is expected). Even if we could identify such products, this approach will miss most of the benefits that flexibility has to offer. For getting the benefits of flexibility, it is only necessary that products with negatively correlated demand be built in the same chain, not necessarily in the same plant. This does not mean that a manufacturer should necessarily create one single chain encompassing all its plants and products. Deciding hor much manufacturing flexibility to invest in requires an analysis of both the benefits and costs. However, since the benefits of flexibility come from creating long chains of products and plants, capacity planning should encompass as many plants and products as possible. 
Consider m products that are manufactured in a plants. The demand for any product $i$ is a random variable and demands for all products are identically normally distributed with

$$
\begin{aligned}
& \mu=\text { expected demand for each product, } \\
& \sigma^{2}=\text { variance in demand for each product, and } \\
& \rho=\text { correlation coefficient between any pair of products demands. }
\end{aligned}
$$

Assuming identical correlation coefficients between all product pairs implicitly restricts $\rho$ to being nonnegative. Also assume that all plants have identical capacity, $C$.

Suppose the products and plants are divided into $K$ chains. Assume that the numbers of plants and products per chain are continuous variables:

$$
\begin{aligned}
& \alpha=\text { number of products } / \text { chain }=m / K \text { and } \\
& \beta=\text { number of plants } / \text { chain }=n / K
\end{aligned}
$$

Wile unrealistic, this assumption greatly simplifies the analysis and makes little difference in the accuracy of the equations developed below. Also, let

$$
\begin{aligned}
& D_{j}=\text { the demand for all products in chain } j \text { and } \\
& S_{j}=\text { the sales of all products in chain } j .
\end{aligned}
$$

Assume that within each chain that product allocation decisions have added enough flexibility to yield the benefits of total flexibility (we have seen that this requires adding only a few product-plant links beyond those needed to create the chain). With this assumption then

$$
S_{j}=\min \left(\beta C, D_{j}\right)
$$

Since $D_{j}$ is the sum of a normally distributed random variables, it is 
also normally distributed with parameters:

$$
\begin{aligned}
& E\left[D_{j}\right]=a \mu \\
& V\left[D_{j}\right]=a \sigma^{2}+a(a-1) \rho \sigma^{2}=\sigma^{2}\left(a^{2} \rho+a(1-\rho)\right) .
\end{aligned}
$$

Let $f_{D}(\bullet)$ and $F_{D}(\bullet)$ be the standard Normal density and cumulative distribution functions, respectively, for $D_{j} \cdot 1$ Then

$$
E\left[S_{j}\right]=\int_{-\infty}^{\beta C} x f_{D}\left(\left(x-E\left[D_{j}\right]\right) / \sqrt{V\left[D_{j}\right]}\right) d x+\beta C\left(1-F_{D}(z)\right)
$$

where $\quad z=\left(\beta C-E\left[D_{j}\right]\right) / \sqrt{V\left[D_{j}\right]}$.

From Winkler et al. (1972), evaluating the integral yields

$$
E\left[S_{j}\right]=a \mu F_{D}(z)-\sigma \sqrt{a^{2} \rho+a(1-\rho)} f_{D}(z)+\beta C\left[1-F_{D}(z)\right]
$$

Let $T=$ total sales for all products $=\Sigma S_{j}$.

$$
\mathrm{j}
$$

Then

$$
\begin{aligned}
E[T] & =\sum_{j=1}^{K} E\left[S_{j}\right] \\
& =m \mu F_{D}(z)-\sigma \sqrt{\left.m^{2} \rho+K_{m}(1-\rho)\right]} f_{D}(z)+n C\left[1-F_{D}(z)\right]
\end{aligned}
$$

$$
\text { where } \quad z=(\beta C-a \mu) / \sigma \sqrt{a^{2} \rho+a(1-\rho)}=(n C-m \mu) / \sigma \sqrt{m^{2} \rho+K m(1-\rho)} \text {. }
$$

1. Equation (A1) and the equations that follow assume that the probability that $D_{\mathrm{j}}<0$ is small. 
Equations (A7) and (A8) show that total sales is a rather complex function of $K$, the number of chains. However, in specific cases the equations simplify significantly. In particular, when total capacity balances total expected demand $(m \mu=n C)$ these equations simplify dramatically. This is an important case because there are many reasons beyond adding flexibility for balancing capacity with expected demand. In this case, $z=0, f_{D}(z)=0.3989$, and $F_{D}(z)=0.5$. Then (A7) becomes:

$$
E[T]=m \mu-0.3989 \sigma \sqrt{\left.m^{2} \rho+K m(1-\rho)^{\prime}\right]}
$$

As this equation shows, when capacity balances expected demand, $E[T]$ is convex in $K$. That is, there are increasing returns to expected sales from reducing the number of chains.

The Figure Al shows this for the following case:

$$
\begin{aligned}
& \mathrm{m}=\mathrm{n}=10, \\
& \mu=\mathrm{C}=100 \text { units, } \\
& \sigma=30 \text { units. }
\end{aligned}
$$

The figure clearly shows that the benefits of chaining for responding to uncertain demand increase as more chaining is done. However, this increase, as well as the overall benefits of flexibility are reduced as product demands are more highly correlated.

Figure A2 shows how varying the number of products and plants affects total sales assuming 1 chain. Hence, in this graph, $\mu=C=100$ units, $\sigma=30$ units, and $\rho=0.0$. This shors that if total flexibility is achieved, expected sales per product increase at a diminishing rate with the number of products and plants. 


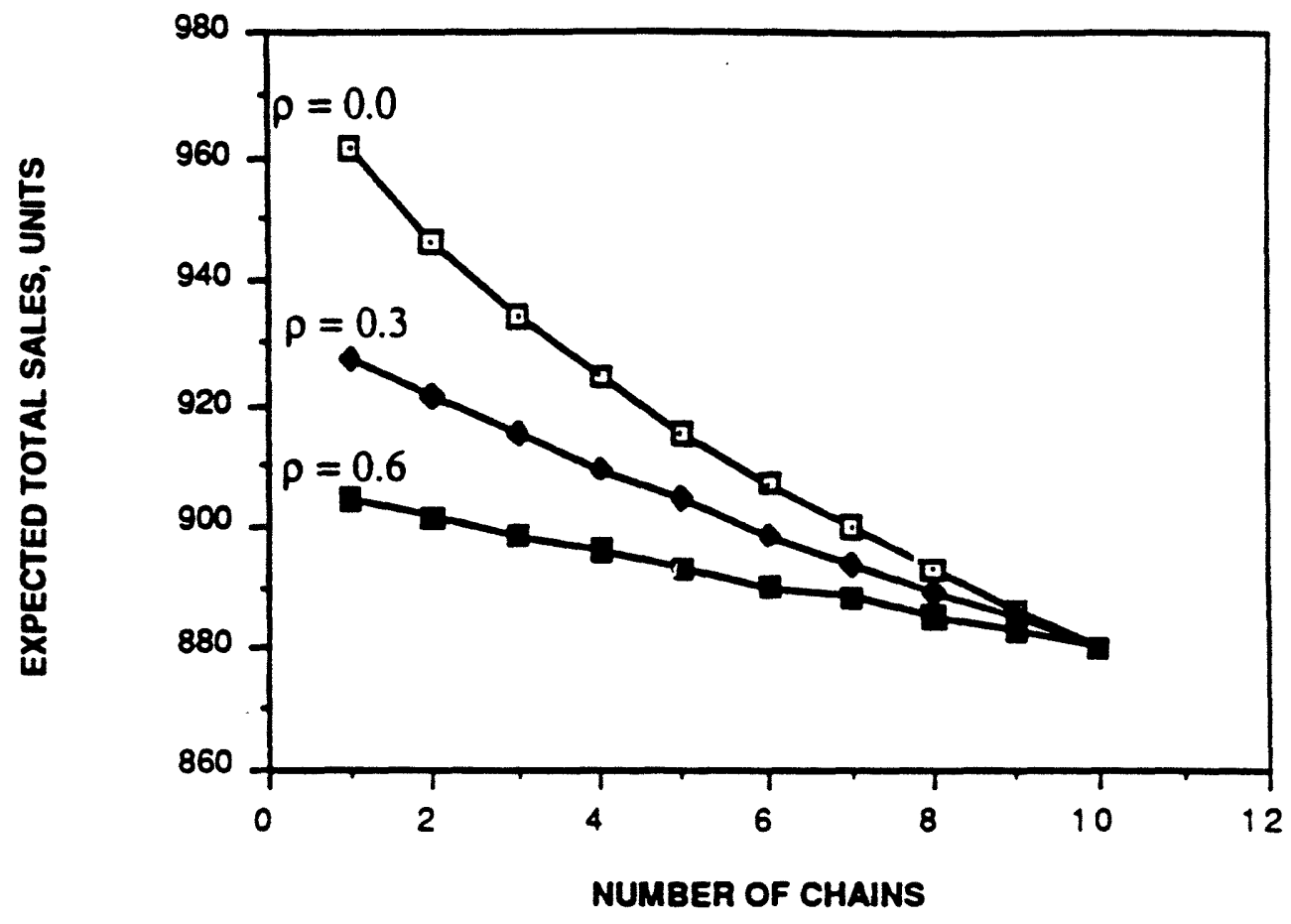

FIGURE A1. IMPACT OF NUMBER OF CHAINS ON SALES.

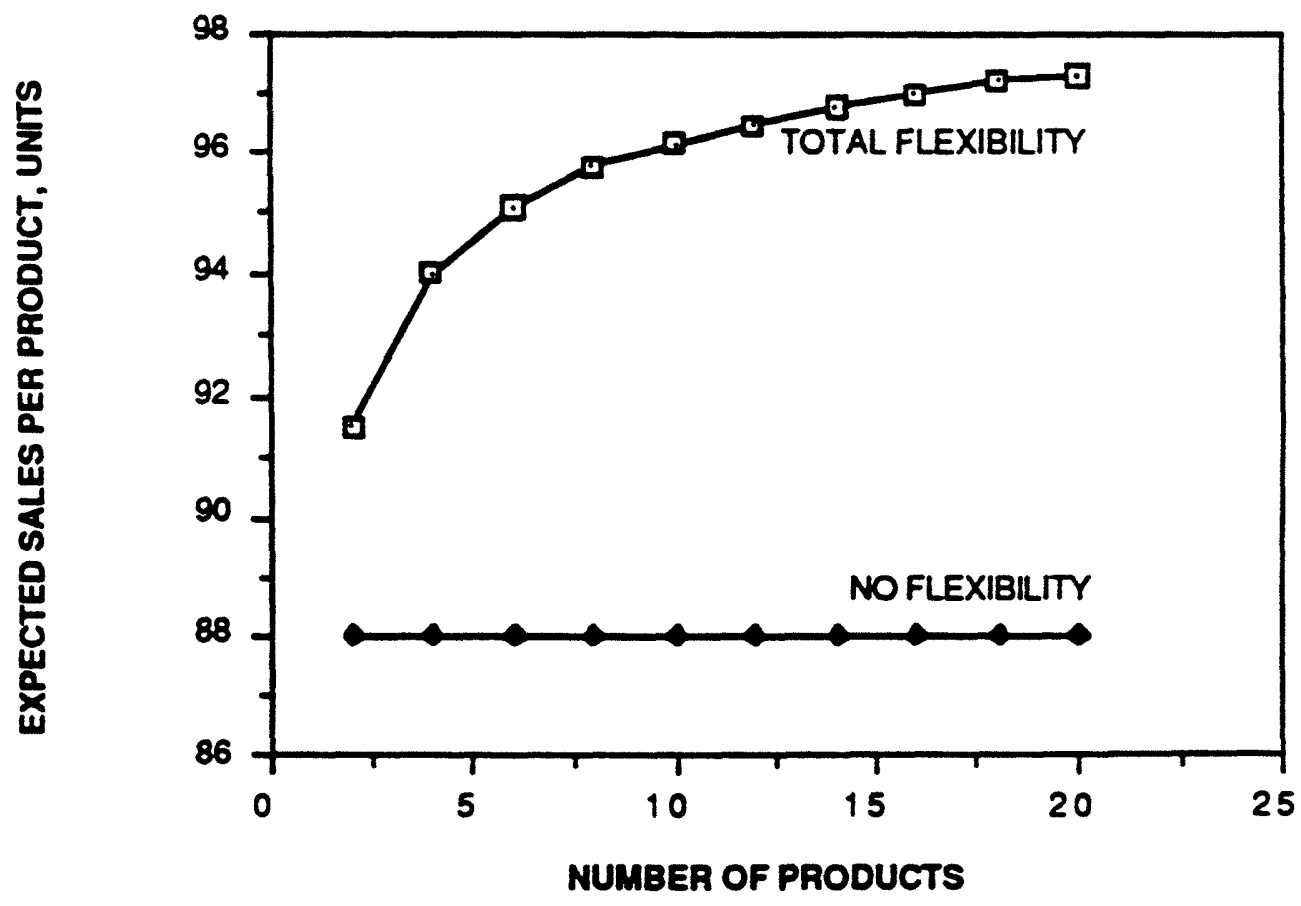

FIGURE A2. IMPACT OF NUMBER OF PRODUCTS ON SALES 


\section{REFERENCES}

Andreou, S. A. (1990). "A Capital Budgeting Model for Product-Mix Flexibility," Journal of Manufacturing and Operations Management, 3(1), $0-0$.

Browne, J., Dubois, D., Rathmill, K., Sethi, S. P., and Stecke, K. E. 1884. "Classification of flexible manufacturing systems," The Fus Magazine, April 1884, 114-117.

Fine, C. H. and Freund, R. M. 1980. "Optimal Investment in Product-Flexible Manufacturing Capacity," Management Science, 36(4), 449-466.

Graves, S. C. and Jordan, W. C. 1991. "An Analytic Approach for Demonstrating the Benefits of Limited Flexibility", GY Research Laboratories Research Publication, forthcoming.

Sethi, A. K. and Sethi, S. P. 1990. "Flexibility in Manufacturing: A Survey," International Journal of Flexible Manufacturing Systems, 2(4), 289-328.

Stecke, K. E. 1983. "Formulation and Solution of Nonlinear Integer Production Planning Problems for Flexible Manufacturing Systems," Management Science, $29(3), 273-288$.

Triantis, A. J. and Hodder, J. E. (1989) "Valuing Production Flexibility When Demand Curves Are Downward Sloping," Working Paper, University of Wisconsin, Madison, WI.

Winkler, R. L., Roodman, G. M., and Britney, R. R. 1872. "The Determination of Partial Moments," Management Science, 19(3), 290-296.

\section{ACKNOKLEDGEMENTS}

We rould like to thank Larry Burns and Bob Glubzinski of the BuickOldsmobile-Cadillac Group and AI Steurer and Rick Robbins of the ChevroletPonitac-GY of Canada Group at General Motors for valuable discussions about capacity planning and manufacturing flexbility that contributed greatly to this research. 